\title{
Endometrial stromal sarcoma presented as endometrial polyp: a rare case
}

\author{
Daniilidis Angelos $^{1 *} \mathbb{D}$, Liberis Anastasios ${ }^{1}$, Miliaras Dimosthenis $^{2}$, Dampali Roxani ${ }^{1}$, Papanikolaou Alexis ${ }^{1}$ and \\ Dinas Konstantinos ${ }^{1}$
}

\begin{abstract}
Endometrial stromal sarcomas are rare malignant mesenchymal tumors, occurring in the age group of 45-55 years. We report a case of low-grade endometrial stromal sarcoma in a 39-year-old woman, whose ultrasound examination suggested a large endometrial polyp. Polypectomy followed by laparoscopic total hysterectomy with bilateral salpingo-oophorectomy was performed. The final histological examination showed no residual disease, implying that the tumor was totally resected during hysteroscopy. This case report highlights that endometrial stromal sarcoma is to be included in the differential diagnosis of endometrial polyp though rare.
\end{abstract}

Keywords: Endometrial stromal sarcoma, Hysteroscopy, Endometrial polyp, Uterine malignancy, Uterine sarcoma, Mesenchymal neoplasm

\section{Introduction}

Endometrial stromal tumors (EST) are rare tumors and according to the latest 2014 WHO classification are divided into four categories: endometrial stromal nodule (ESN), low-grade endometrial stromal sarcoma (LGESS), high-grade endometrial stromal sarcoma (HGESS), and undifferentiated uterine sarcoma (UUS) [1]. ESS accounts for $<1 \%$ of all uterine tumors with an annual incidence of $1-2$ per million women $[2,3]$.

Although the early diagnosis and treatment is essential for the prognosis, it is often delayed due to the nonspecific signs and symptoms [4].

In our article, we report a case of low-grade endometrial stromal sarcoma, presented as an endometrial polyp in a young patient, with a brief review of its incidence, diagnosis, management, and prognosis.

\section{Case report}

Endometrial stromal sarcoma (ESS) is a rare clinical entity, particularly among young women. Herein, we report

\footnotetext{
* Correspondence: angedan@hotmail.com

'2nd Department of Obstetrics and Gynecology, Hippokratio General Hospital, School of Medicine, Aristotle University of Thessaloniki, Thessaloniki, Greece

Full list of author information is available at the end of the article
}

a case of a 39-year-old woman, gravida 2, para 2, with no history of exposure to tamoxifen neither to unopposed estogens, who was referred to our center in March 2019 due to abnormal vaginal bleeding. The transvaginal ultrasound examination (Fig. 1) suggested a large endometrial polyp and its hysteroscopict removal was scheduled. Grossly, the tumor measured $3 \times 2 \times 2$ $\mathrm{cm}$, and was a relatively circumscribed, lobulated oval mass. Although the hysteroscopic impression (Fig. 1) was that of an endometrial polyp the histological examination showed LG (low grade)-ESS (Fig. 2). The tumor cells were spindle-shaped with mild atypia, and few mitoses (3-4 per 10 high power fields), and formed fascicles that infiltrated between the muscle bundles of the myometrium. Immunohistochemically, the tumor cells were positive to CD10 and negative to h-caldesmon, desmin, and a-smooth muscle actin. Preoperatively, CT (computerized tomography) scan was reported as with no suspicious findings and total hysterectomy with bilateral salpingo-oophorectomy was then decided.

Total hysterectomy with bilateral salpingooophorectomy was completed laparoscopically with no intraoperative or postoperative complications. The final histological examination showed no residual disease,
Springer Open (c) The Author(s). 2020 Open Access This article is licensed under a Creative Commons Attribution 4.0 International License, which permits use, sharing, adaptation, distribution and reproduction in any medium or format, as long as you give appropriate credit to the original author(s) and the source, provide a link to the Creative Commons licence, and indicate if changes were made. The images or other third party material in this article are included in the article's Creative Commons licence, unless indicated otherwise in a credit line to the material. If material is not included in the article's Creative Commons licence and your intended use is not permitted by statutory regulation or exceeds the permitted use, you will need to obtain permission directly from the copyright holder. To view a copy of this licence, visit http://creativecommons.org/licenses/by/4.0/. 


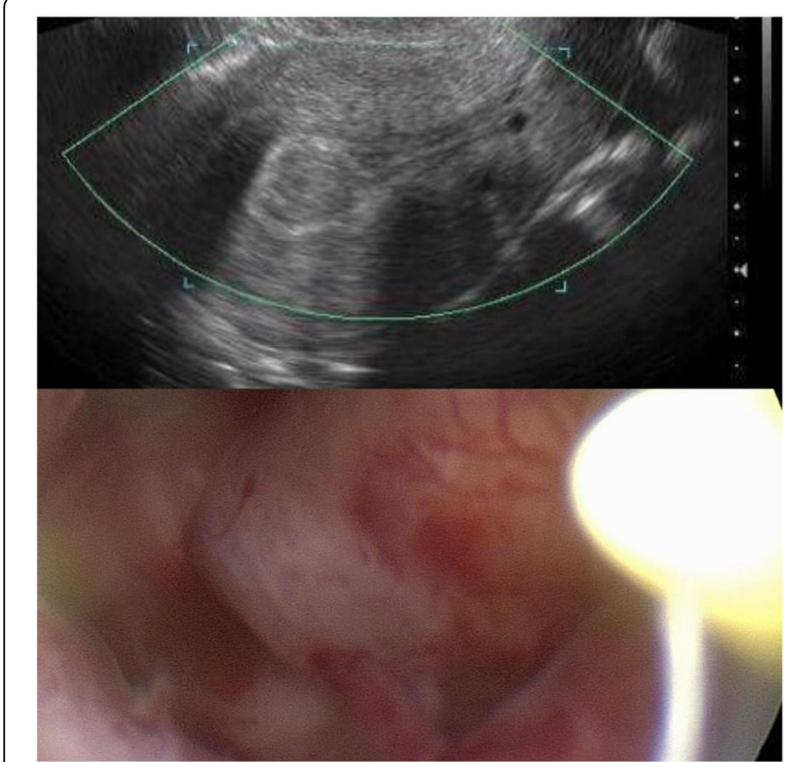

Fig. 1 Up: Ultrasound image. Down: hysteroscopic view

implying that the tumor was totally resected during hysteroscopy. In conclusion, our patient with stage Ia LGESS was assessed by the oncology council and was recommended observation alone with no need of adjuvant treatment complying with the National Comprehensive Cancer Network (NCCN) consensus guidelines [5].

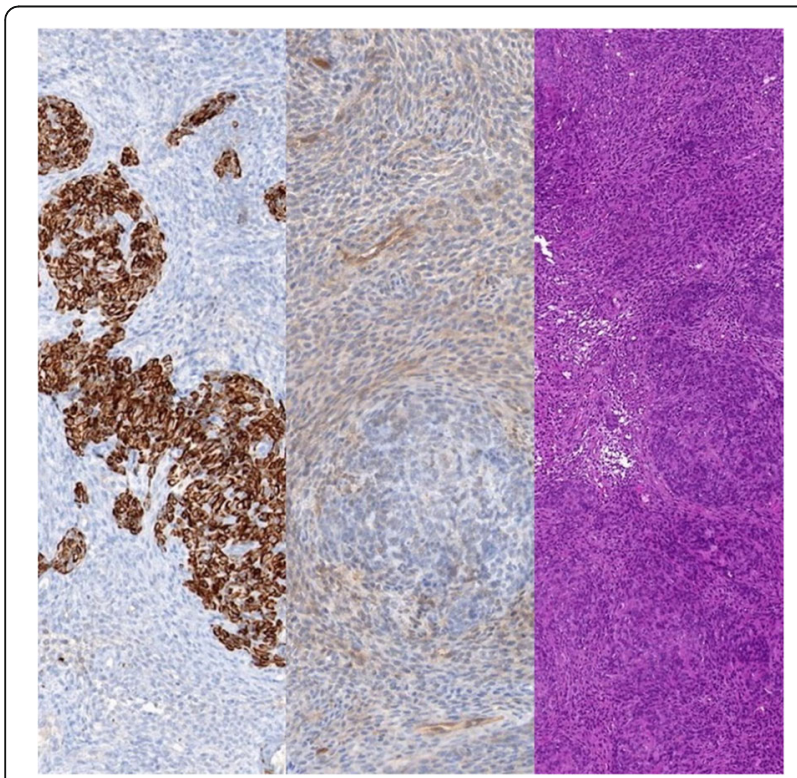

Fig. 2 Left: immunohistochemical staining for desmin, $\times 100$ magnification. Middle: immunohistochemical staining with CD10, $x$ 100. Right: Hematoxylin-eosin stain, $\times 40$

\section{Discussion}

The ESS are rare tumors and the mean age of the affected women ranges between 45 and 55 years and the main symptoms and findings are abnormal uterine bleeding, pelvic pain, uterine mass, or endometrial polyp. The only way to definitively rule out the presence of sarcomatous tissue in such cases is the removal of the myomatosus or/and endometrial lesion [6]. Our patient presented at 39 years due to abnormal vaginal bleeding, which is a rarity in itself. Due to their non-specific signs and symptoms LG ESS tumors are difficult to diagnose in the early stage or preoperatively [4].

The definitive treatment is total abdominal hysterectomy, bilateral adnexectomy, and excision of all grossly detectable tumor. Adjuvant radiotherapy (RT) may be used in order to achieve a high-locoregional control rate and should be determined on a case-by-case basis. In cases of LG-ESS stage 3-4 and in cases of recurrent disease, endocrine therapy with medroxyprogesterone, tamoxifen, gonadotropin-releasing hormone (GnRH) analogues and aromatase inhibitors is possibly indicated. With regards to the role of lymphadenectomy, it is not indicated except for cases with suspicious lymphadenopathy noted on preoperative imaging, since the risk of lymph node metastases is around 10\% [7-10].

In our case, the 39-year-old patient with stage Ia LGESS was assessed by the oncology council and was recommended observation alone with no need of adjuvant treatment.

Regarding prognosis, tumor stage and patient's age are the most important prognostic factors. The 5-year survival rate is over $90 \%$ for patients with tumor stage I-II, while it is around $50 \%$ for those with stages III-IV. The risk of recurrence in LG-ESS is estimated to be $10-20 \%$. Recurrences may occur after more than 10-30 years and may appear locally in the vagina, pelvis, or as distant metastases. There is no association between distant metastases and recurrences with positive lymph nodes. In cases with negative lymph node status, the recurrence rate is reported to be up to $30 \%$ within 2 years [11].

\section{Conclusions}

Taking into account the fact that ESS is a rarely encountered malignancy of uterus, an accumulation of reports of this clinical entity is, therefore, essential to better understand its natural course and to improve treatment options. Furthermore, this case report highlights that ESS is to be included in the differential diagnosis of endometrial polyp though rare.

\section{Abbreviations}

CT: Computerized tomography; ESN: Endometrial stromal nodule; ESS: Endometrial stromal sarcoma; EST: Endometrial stromal tumors; GnRH: Gonadotropin-releasing hormone; HG: High grade; LG: Low grade; 
NCCN: National Comprehensive Cancer Network; RT: Radiotherapy;

UUS: Undifferentiated uterine sarcoma; WHO: World Health Organization

\section{Acknowledgements}

N/A

Authors' contributions

All authors contributed to the selection of data and the presentation of the manuscript. All authors read and approved the final manuscript.

\section{Funding}

No funding to declare

\section{Availability of data and materials}

All data and material used are available.

\section{Ethics approval and consent to participate}

N/A as it is a case report.

\section{Consent for publication}

Patient consented for the publication

\section{Competing interests}

The authors declare that they have no competing interests. This study was conducted without any financial support. The authors state that the views expressed in the submitted article are their own and not the official position of the institution or funder.

\section{Author details}

'2nd Department of Obstetrics and Gynecology, Hippokratio General Hospital, School of Medicine, Aristotle University of Thessaloniki, Thessaloniki, Greece. ${ }^{2}$ Laboratory of Histology \& Embryology, Faculty of Medicine, Aristotle University of Thessaloniki, Thessaloniki, Greece.

Received: 3 April 2020 Accepted: 19 May 2020

Published online: 01 June 2020

\section{References}

1. Ali RH, Rouzbahman M (2015) Endometrial stromal tumours revisited: An update based on the 2014 WHO classification. Journal of Clinical Pathology. 68(5):325-332

2. Tavassoli FA, Devilee P (2003) WHO Classification of Pathology and genetics of tumours of the breast and female genital organs. IARC Press, Lyon, pp 233-236

3. Hoang L, Chiang S, Lee CH (2018) Endometrial stromal sarcomas and related neoplasms: new developments and diagnostic considerations. Pathology. 50(2):162-177

4. Fekete PS, Vellios F (1984) The clinical and histologic spectrum of endometrial stromal neoplasm: a report of 41 cases. Int J Gynecol Pathol 3: 198-212

5. National Comprehensive Cancer Network (NCCN) (2017) NCCN Clinical Practice Guidelines in Oncology. Available via DIALOG. http://www.ncen. org/professionals/physician gls/f guidelines.asp. Accessed 20 March 2020.

6. Nappi L, Mele G, Angioni S, Di Spiezio SA, Cicinelli E, Greco P (2014) Uterine leiomyosarcoma: report of three cases and review of the literature. Eur J Gynaecol Oncol. 35(3):328-331

7. Gadducci A, Cosio S, Romanini A, Genazzani AR (2008) The management of patients with uterine sarcoma: a debated clinical challenge. Crit Rev Oncol Hematol. 65:129-142

8. Palombaa S, Falboa A, Mocciaroa R, Russob T, Zulloa F (2009) Laparoscopic treatment for endometrial cancer: A meta-analysis of randomized controlled trials (RCTs). Gynecol Oncol. 112:415-421

9. Lindner T, Pink D, Kretzschmar A, Mrozek A, Thuss-Patience PC, Reichardt P (2005) Hormonal treatment of endometrial stromal sarcoma: a possible indication for aromatase inhibitors. J Clin Oncol. 23:9057

10. Benson C, Miah AB (2017) Uterine sarcoma - current perspectives. Int Womens Health 9:597-606

11. Thiel FC, Halmen S (2018) Low-Grade Endometrial Stromal Sarcoma - a Review. Oncol Res Treat. 41(11):687-692

\section{Publisher's Note}

Springer Nature remains neutral with regard to jurisdictional claims in published maps and institutional affiliations.

\section{Submit your manuscript to a SpringerOpen ${ }^{\circ}$ journal and benefit from:}

- Convenient online submission

- Rigorous peer review

- Open access: articles freely available online

- High visibility within the field

- Retaining the copyright to your article

Submit your next manuscript at $\boldsymbol{\nabla}$ springeropen.com 